WILLIAMS, J. D., C. KASS, y L. AVILA.

"History of Discovery of the Patagonian Lizards"

\title{
En prensa:
}

\section{SPRINGER NATURE}

Dear Dr. Jorge D. Williams,

I am happy to inform you on behalf of Springer Nature that the proofs of your book chapter "History of Discovery of the Patagonian Lizards" are now available.

We have introduced a new online correction system, which allows you to directly incorporate your corrections, thereby eliminating any possible misunderstandings arising from misinterpreted handwritten corrections. This ensures that publication of the book is not delayed by additional rounds of correction.

Please note that the only changes that can be made at this stage are limited to typographical mistakes and serious errors in content.

Please check the author/editor names very carefully to ensure correct spelling, correct sequence of given and family names, and that the given names and family names have been correctly designated (NB the family name is highlighted in blue). Please also provide an answer to any Author Queries raised during typesetting. Unanswered queries will lead to delays in publication.

To access your proofs, please click on the link below, or copy and paste it into your browser window:

https://eproofing.springer.com/books v2/index.php?token=JcXXYOIHeS6BgzUGivjM2-

$\underline{\mathrm{HFL} 2 \mathrm{dbm} 7 \mathrm{bp} 3 \mathrm{nCPOQThzrO}}$

If you are responsible for returning the proof correction, please return the corrected proofs by 18 March 2020.

If you have any questions, please feel free to contact me.

We welcome your comments and suggestions. Your feedback helps us to improve the system.

Cordially,

\section{S.Cathrine}

